\title{
Male-male mounting and the unreliability of body size as a character for mate choice in male Japanese beetles (Popillia japonica Newman)
}

\author{
Paul V Switzer ${ }^{1 *}$, Patrick S Forsythe ${ }^{2}$ and Kipp C Kruse ${ }^{1}$
}

\begin{abstract}
Background: Same-sex pairing is common in many animal species. In many insects, same-sex pairing is often thought to be a result of poor sexual discrimination (i.e., a mistake), but few detailed studies of the mechanisms underlying the mistaken pairing have been conducted. Previous studies have found that in the field, a small proportion of Japanese beetle (Popillia japonica) mating pairs consist of two males instead of a male and a female. In the current study, we investigated the relationship between body size, the tendency to mount other males, and the duration of these mounts, in laboratory experiments on male Japanese beetles.
\end{abstract}

Results: In the first experiment, we observed male-male mounting in all-male groups in which each male had been uniquely marked. Males of all sizes were likely to mount other males and extend their aedeagus (copulatory organ), but the mounts were longer, and aedeagus extension was more likely to occur, if the mounted beetle (in the 'female' position) was larger than the mounting beetle (in the 'male' position). In the second experiment, we observed male-female behavior in mixed-sex groups. Females did not immediately copulate with males that had mounted them. If copulation did occur, males tended to remain on the back of females for an extended period of time. Males that mounted other males in mixed-sex groups tended to mate subsequently with a female and then stay with her.

Conclusions: We propose that the minimal physical difference between the sexes, in combination with benefits to the males of rapidly attempting to pair with any available female, explains the tendency for males to mount other males. Extended mounts may occur because larger individuals are more likely to be female and because of selection on males to persist in a copulation attempt when females do not immediately copulate with a male.

Keywords: Mate choice; Japanese beetle; Sexual discrimination; Homosexual behavior; Insect; Body size

\section{Background}

Same-sex pairing occurs in a wide variety of species and contexts (for reviews, see Thornhill and Alcock 1983; Bagemihl 1999; Harari et al. 2000; Bailey and Zuk 2009). In many insects, same-sex pairing is not thought to have any direct benefit to the mounting male, that is, they are making mistakes (e.g., Harari et al. 2000). However, although same-sex pairings may be mistakes, in some species, these mistakes do not appear to be the result of random pair formation. For instance, studies of three species - a water bug (Palmacorixa nana; Aiken 1981), the sugarcane root borer weevil (Diaprepes abbreviatus; Harari et al. 2000),

\footnotetext{
* Correspondence: pvswitzer@eiu.edu

'Department of Biological Sciences, Eastern Illinois University, Charleston, IL 61920, USA

Full list of author information is available at the end of the article
}

and the Japanese beetle (Popillia japonica; Switzer et al. 2004) - found that male-male pairs tended to consist of smaller males that had mounted larger males. In all three species, females tend to be larger than males, and these studies suggested that males might use the imperfect cue of body size for determining the individuals they would mount. In other words, the homosexual mounting is a result of mistaken sexual identity.

Detailed investigations of this 'mistaken identity' hypothesis (Scharf and Martin 2013) for same-sex pairing in such species would be valuable for at least two reasons. First, although same-sex pairings may be brief in some cases ( 1 to $2 \mathrm{~s}$ in the case of Palmacorixa nana; Aiken 1981) and therefore of little consequence to males, in other cases, pairings may last for an extended period of time leading to lost mating opportunities, energetic costs, 
and lowered survival (MØller 1987; Dickinson 1992, 1995; Shine et al. 2000; Maklakov and Bonduriansky 2009). Second, examining the types of mistakes that are made in same-sex behavior could yield insight into the heterosexual mating behavior and overall mating system of a species. For example, one might be able to use the characteristics of mistaken choices to understand the sex recognition system and mate quality recognition system a species uses. This knowledge could then be applied to examine whether these two recognition systems reinforce each other (i.e., the cues used indicate a high quality mate and the correct sex) or are in conflict (i.e., the cues used indicate a high quality mate but the wrong sex), much as species recognition and mate preference may be reinforcing or conflicting (Ryan and Rand 1993; Pfennig 1998, 2000; Hankison and Morris 2003).

In this study, we conducted detailed observations on male-male mounting in the Japanese beetle (Popillia japonica Newman; Coleoptera: Scarabaeidae). Japanese beetles were introduced into the USA in the early 1900s and are pests of over 300 species of plants as adults (Fleming 1972; Potter and Held 2002). Males pair with newly emergent, virgin females to whom they are attracted by a sex pheromone (Ladd 1970a; Tumlinson et al. 1977). Females that have mated stop producing this pheromone; non-virgin females and males aggregate and mate on food plants as a result of attraction to plant kairomones (Loughrin et al. 1995). Density in these aggregations can be very high, e.g., as many as 73 individuals have been found on a single peach fruit (Switzer et al. 2004). The typical mating sequence (Barrows and Gordh 1978; personal observations) involves the male orienting toward a female, climbing on top of her and aligning his body to her body (anterior to posterior), extension and insertion of his aedeagus, transfer of sperm, and removal of aedeagus. Following removal of the aedeagus, males remain mounted on the female and guard her for an extended period (up to several hours; Barrows and Gordh 1978; Saeki et al. 2005a, b; Switzer et al. 2008; Tigreros and Switzer 2008). While guarding, males may incur thermoregulatory and/or energetic costs (Saeki et al. 2005a). Females and males mate multiply over their lifetimes, and females lay multiple clutches of eggs in the soil (Fleming 1972; Van Timmeren et al. 2000). Females tend to be larger than males (female body width is approximately $7.5 \%$ larger than male body width on average), but there is considerable overlap in their size distributions (Van Timmeren et al. 2000; Switzer et al. 2001).

In a previous study (Switzer et al. 2004), we found that a small percentage (approximately $3 \%$ ) of pairs in the field consisted of two males. These male-male pairs were most common in the afternoon, when the frequency of male-female pairing was the lowest (Switzer et al. 2001, 2004). In the laboratory, male-male mounting was more common at high densities and with male-biased sex ratios (Switzer et al. 2004). In the field and laboratory, the top male of a male-male pair (in the 'male position') tended to be smaller than the bottom beetle (in the 'female position'), and Switzer et al. (2004) suggested that these pairs were a result of mistakes by the mounting male. The goals of the current study were to further investigate the mistaken identity hypothesis by examining how male size affected the likelihood of male-male mounting and the duration of these pairs. We predicted that the probability of male-male mounting and the duration of pairing would increase with increasing size of the mounted male. In addition, we examine male-female mating behavior as a comparison to help explain why extended male-male mounts may occur in this species. We then present a conceptual model for why male-male mounting occurs and why male-male pairs are relatively rare in the field. We conclude with the implications our findings have for the previously observed male preferences for large females in this species (Saeki et al. 2005c).

\section{Methods}

Beetles were collected on food plants in the morning (primarily sassafras Sassafras albidum, peach Prunus persica, and soybean Glycine max). Individuals were used in only one experiment, and all beetles were used in the afternoon of the day of capture. Males were separated from females using foreleg morphology (Smith and Hadley 1926).

\section{All-male experiment}

To examine characteristics of male-male mounting in general and body size effects on pairing in particular, we conducted an experiment in which the behavior of a group of males was observed for a period of time. Males were marked individually by attaching a numbered bee tag (Thorne Ltd., Wragby, UK) to their pronotum using super glue (Tigreros and Switzer 2008). Trials were conducted in the afternoon in the laboratory at approximately $28^{\circ} \mathrm{C}$.

Groups of 10 randomly chosen males were used in each trial. Males were placed in a small glass dish (10-cm diameter, 4-cm height) in which two cherry leaves had been attached to the sides in such a manner that they protruded into the dish perpendicular to the floor of the dish. A layer of moist paper towel was put in the bottom of the dish, and the top of the dish was covered with a piece of clear acrylic plastic (Switzer et al. 2004).

For $30 \mathrm{~min}$, an observer watched the dish directly and recorded data on every male-male mount. In order to be considered a male-male mount, the top male's behavior had to be consistent with sexual behavior exhibited toward a female (i.e., in terms of grasping, orientation, and posture, which we lump into the term 'mount'; Barrows and Gordh 1978; Switzer et al. 2004). Thus, simple contacts between males were not included in these data. For each mount, 
the observer recorded the start and end of each mount using a continuously running stopwatch (to determine the duration of time a male was on top of another male in a sexual or mate-guarding position), whether the top male extended his aedeagus (i.e., his copulatory organ) during the mount, and whether the mount ended because the top male left (simply crawled away), the bottom male left (kicked and pushed the top male off with his legs), both males left at the same time (both simply crawled away), or for unknown cause. After a trial, all males were frozen and their size was determined subsequently by recording the maximum body width using a microscope with an ocular micrometer; body width is a good measure of overall body size (Van Timmeren et al. 2000). A total of 17 replicates were conducted using a total of 170 males. The sizes of the males did not vary significantly among replicates with respect to their means (ANOVA, $F_{16,153}=1.01, P=0.45$ ) or variances (Bartlett's test, $F=0.84, d f=16, P=0.64$ ).

To allow for the combination of data among trials, for some analyses, we used the size rank of a male within his group of 10 males, with ' 1 ' being the smallest and ' 10 ' being the largest. Males of the same size within a trial were given the same size rank. In addition, to investigate how the sizes of the top and bottom male of a particular pair related, as well as how their relative sizes correlated with the duration of their pair, we used the pairing with the longest duration for each male that appeared on top of a pair. We used the longest duration because this demonstrates the largest 'commitment' by the mounting male and because longest mount would likely have the largest evolutionary consequence for that male.

\section{Mixed-sex experiment}

In order to compare some aspects of male-male mounts to heterosexual mounts, we conducted a series of trials in which five males and five females were marked and placed in a dish as described for the all-male trials. Females were obtained with males from food plants (see above); because they were on food plants, they were all assumed to have mated at some point prior to our experiment (Fleming 1972). In these mixed-sex trials, we recorded the beginning of all mounts and, as much as possible, recorded the time of the first extension of the aedeagus, the start and duration of the copulation, and the end of the mount. Copulation is fairly easy to observe: males insert their aedeagus for approximately $2 \mathrm{~min}$ (see 'Results' section), and then there is a very conspicuous withdrawal from the female. In male-male mounts, we never observed a male insert his aedeagus during this experiment. Due to the position of the beetles in the dish, some of these events were not visible for all mounts; thus, one reason sample sizes differ among tests is because the time of all events was not recorded for all mounts. Because male-female mounts tended to last longer than male-male mounts (see 'Results'), we recorded these pairing events for $1 \mathrm{~h}$, and then, for 1 additional hour, we continued to observe any pairs still together at the end of the first hour. In other words, in the second hour of observation, we followed the fates of existing pairs but did not record new pairing behavior. Following a trial, all individuals were frozen for later size measurement; some individuals lost their tags prior to measurement, causing sample sizes to differ among some size comparisons. A total of 15 replicates were conducted.

\section{Statistical analyses}

Statistical analyses were conducted on JMP 3.1 (SAS Institute, Inc., Cary, NC, USA) or StatView 4.51 (Abacus Concepts, Berkeley, CA, USA). Means are presented \pm SE. Durations were log transformed to meet assumptions of normality for parametric tests. Three simple regressions, rather than a single multiple regression, were used to relate the duration of a mount to the size of the top male and bottom male, and the size difference between the top and bottom male; we then compare these regression models to infer which size metric better explains variation in mount duration using standardized coefficients (i.e., ' $b$ ' value). We used comparisons of simple regressions because although the size of the bottom and top male tend not to be related (see 'Results'), the sizes of the top and bottom male in a mount are correlated with their size difference (e.g., if a male is relatively small, the size difference will tend to be larger). Non-parametric analyses were used for comparisons involving size ranks. $P$ values for nonparametric statistics take tied values into account when appropriate.

\section{Results}

\section{All-male experiment}

General

In the 17, 10-male trials, there were 191 male-male mounts. In each trial, $2.2 \pm 0.2$ males participated as just a top male, $2.5 \pm 0.1$ males as just a bottom male, $3.6 \pm 0.4$ males were both a top and a bottom male, and $1.7 \pm 0.4$ males did not pair with another male.

The 191 pairs had an average duration of $312 \pm 62.6 \mathrm{~s}$ (range 1 to $8,010 \mathrm{~s}$, median $=47 \mathrm{~s}$ ), but the distribution was highly skewed (Figure 1); 106/191 (55\%) of pairs lasted less than $1 \mathrm{~min}$ compared to 36 (19\%) that lasted over $5 \mathrm{~min}$. In $74 / 191$ (39\%) pairs, the top male extended his aedeagus. We observed no pairs with a successful 'copulation' (i.e., aedeagus insertion).

For 190/191 (99\%) pairs, the termination of the pair was observed. In $158 / 190$ (83\%) pairs, the top male ended the pairing; in $16 / 190$ (8.5\%), the bottom male ended the pairing; and in $16 / 190$ (8.5\%), both males ended the pairing. In 38/190 (20\%) pairs, the bottom male was seen to resist by using his legs to push off the mounting male. 


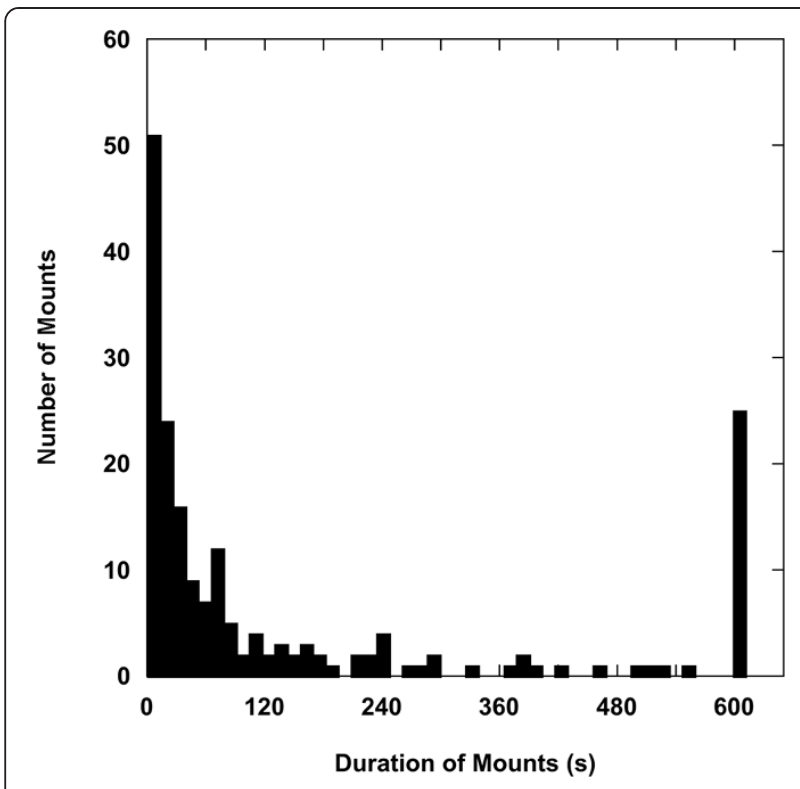

Figure 1 Frequency histogram of the durations of all male-male mounts for Japanese beetles (Popillia japonica). Data are from the 10-male trials ( $N=191$ pairs). The last bar includes all mounts with durations longer than $600 \mathrm{~s}$ (range of 653 to 8,010 s).

\section{Characteristics of male-male pairs}

Using a male's size rank within a trial, we investigated whether size was correlated with his tendency to be located on the top, bottom, or both $(N=143$ males). Male size rank (1 to 10) was not related to the number of mounts for which the individual was on top (Spearman correlation, $r_{\mathrm{s}}=0.03, z=0.35, P=0.73$ ). However, as male size rank increased, so did the number of mounts in which he was on the bottom $\left(r_{\mathrm{s}}=0.22, z=2.63, P=0.009\right)$, and for those males that were the bottom male for at least one pair, larger males spent more time on the bottom per mount $\left(r_{\mathrm{s}}=0.26, z=2.65, P=0.008\right)$. For males that were the top male for at least one pair, smaller males spent relatively more time on top per pair than larger males $\left(r_{\mathrm{s}}=-0.25, \quad z=2.47, \quad P=0.01\right)$. Thus, relatively small males tended to be on the top, and relatively large males tended to be on the bottom.

Overall, the size of the top and bottom males in a pair did not differ consistently (top $5.75 \pm 0.03 \mathrm{~mm}$; bottom $5.79 \pm 0.3 \mathrm{~mm} ; N=101$; paired $t$ test, $t=0.84, P=0.40$ ) nor were they correlated $(r=0.059$, Fisher's $r$ to $z, P=0.56)$. However, a significant, negative relationship existed between the size of the top male and the mount duration $\left(b=-0.22, F_{1,99}=4.85, P=0.03\right)$, and a significant positive relationship existed between the size difference of the bottom versus top male (hereafter referred to as 'size disparity') and the duration of the pair (Figure 2; $b=0.29 ; F_{1,99}=8.92, P=0.0036$ ); the relationship between the size of the bottom male and pair duration did

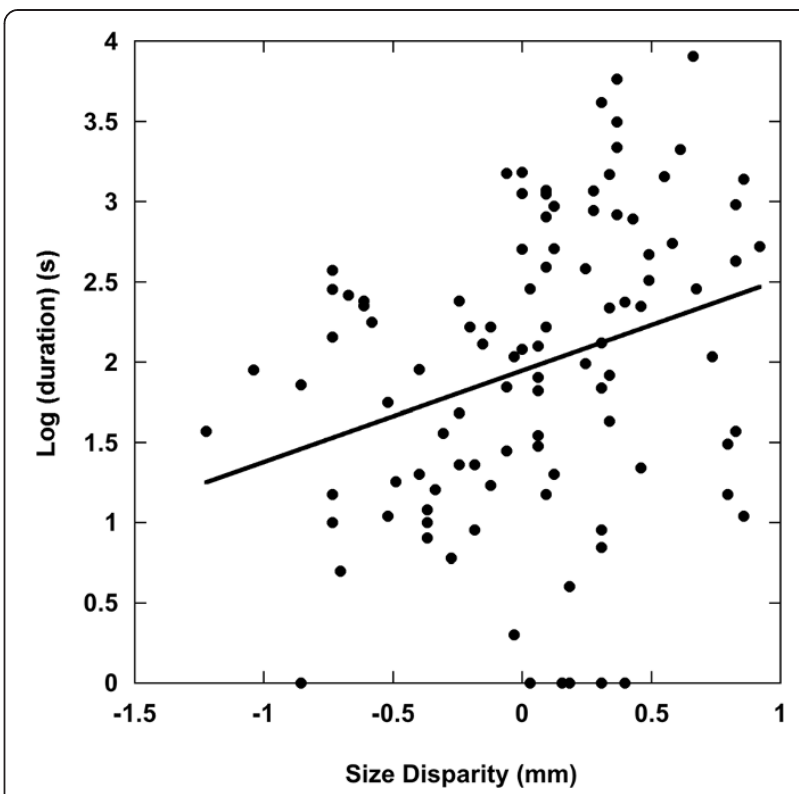

Figure 2 Size disparity versus log (duration of male-male mounts) for Japanese beetles (Popillia japonica). Size disparity = bottom male size minus top male size. Data are from the 10-male group experiment. The line represents a simple linear fit to these data. Data include only the longest pairing for each top male ( $N=101$ pairs).

not reach statistical significance $\left(b=0.18, F_{1,99}=3.27\right.$, $P=0.07)$. Therefore, mounts lasted longer if the top male was relatively small or the size disparity was relatively large. Of these two significant patterns, the relationship between size disparity and duration seems to be stronger.

Male-male mounting, even for an extended mount, was not limited to small males; large males did mount other males for longer than $1 \mathrm{~min}$. For example, of the 55 males that were larger than the mean male size and that mounted another beetle, 31/55 (56\%) had longest mounts that lasted more than $1 \mathrm{~min}$. For those males larger than the mean $+1 \mathrm{SD}, 12 / 20(60 \%)$ had longest mounts over $1 \mathrm{~min}$. Interestingly, the fifth largest male in the entire experiment had a mount of a very long duration (1,176 s); for that mount, he was mounted on a male that was even larger than he was.

Still using the longest mount per male, mounts in which the aedeagus was extended were significantly longer in duration than those with no extension (extended $=931 \pm$ $206 \mathrm{~s}, N=51$; not extended $=96.3 \pm 39.3 \mathrm{~s}, N=50 ; t=10.6$, $P<0.0001)$. Mounts in which the aedeagus was extended had significantly larger bottom males (extended = $5.90 \pm 0.04 \mathrm{~mm}, N=51$; not extended $=5.67 \pm 0.05 \mathrm{~mm}$, $N=50 ; t=3.53, P=0.0006)$ and larger size disparities (extended (bottom size-top size) $=0.20 \pm 0.05 \mathrm{~mm}$, $N=51$; not extended $=-0.12 \pm 0.07 \mathrm{~mm}, N=50 ; t=3.53$, $P=0.0006)$ but no differences in the size of the top male 
(extended $=5.71 \pm 0.05 \mathrm{~mm}, \quad N=51 ;$ not extended $=$ $5.79 \pm 0.05 \mathrm{~mm}, N=50 ; t=1.22, P=0.23)$. This suggests that a male of any size will extend his aedeagus when mounting another male, but this is more likely to happen if the male he is mounting is relatively large and/or is larger than him.

\section{Mixed-sex experiment}

In the 15 mixed-sex trials, a total of 96 pairs formed; 33/ $96(34 \%)$ of these were male-male pairs, while 63/96 (66\%) were male-female pairs.

Copulatory behavior often occurred quickly after a male mounted a female, but variation in the timing did exist. In heterosexual mounts, males typically began extending their aedeagus and probing shortly after mounting (mean latency $=35.6 \pm 7.1 \mathrm{~s}$, range 1 to $273 \mathrm{~s}$, median $20 \mathrm{~s}$ ), with $70 \%$ of them extending their aedeagus within $30 \mathrm{~s}$. Males began copulating $272.0 \pm 100.5 \mathrm{~s}$ (range 7 to $4783 \mathrm{~s}$, median $70 \mathrm{~s}$ ) after mounting, with $82 \%$ beginning copulation within 5 min of mounting; this copulation occurred with an average of $235.7 \pm 99.9 \mathrm{~s}$ (median $=52 \mathrm{~s}$ ) after the initial probe attempt with the aedeagus. Thus, although many copulations began within a minute, copulation did not begin as soon as a male attempted to insert his aedeagus and a fraction of males did not copulate with the female for many minutes after mounting. In contrast to the variable latency until copulation, copulation itself was of remarkably consistent duration $(120.3 \pm 4.2 \mathrm{~s}, N=47$, median $121 \mathrm{~s}$ ), with no copulations lasting under $1 \mathrm{~min}$ and only one lasting more than $3 \mathrm{~min}$.

Most cases of male-female mounting resulted in a copulation. Of the 63 male-female pairs, only 9 (14\%) ended without copulation and 5 of these 9 (55\%) mounts lasted less than $45 \mathrm{~s}$. Comparing mounts with a copulation to those without a copulation, no significant difference was found between the sizes of males (with copulation $=5.84 \pm$ $0.03 \mathrm{~mm}, N=48$; without copulation $=5.97 \pm 0.10 \mathrm{~mm}$, $N=10 ; t=1.58, P=0.12$ ), sizes of females (with copulation $=6.38 \pm 0.052 \mathrm{~mm}, N=54 ;$ without copulation $=$ $6.45 \pm 0.12 \mathrm{~mm}, N=9 ; t=0.50, P=0.62$ ), or the size difference between male and female (with copulation = $0.53 \pm 0.067 \mathrm{~mm}, N=48$; without copulation $=0.48 \pm$ $0.16 \mathrm{~mm}, N=9 ; t=0.30, P=0.76)$.

Male-female pairs usually lasted for an extended period of time. All of the male-female pairs with a copulation $(54 / 54 ; 100 \%)$ lasted at least $20 \mathrm{~min}$, with $49 / 54$ (91\%) lasting more than $1 \mathrm{~h}$ and 49/54 (81\%) lasting more than $2 \mathrm{~h}$. Comparing pairs that lasted longer than $2 \mathrm{~h}$ with those that did not, no significant difference was found between the sizes of males (more than $2 \mathrm{~h}=5.84 \pm$ $0.034 \mathrm{~mm}, N=39$; less than $2 \mathrm{~h}=5.86 \pm 0.067 \mathrm{~mm}, N=9$; $\mathrm{t}=0.24, \mathrm{P}=0.81$ ), sizes of females (more than $2 \mathrm{~h}=6.43 \pm$ $0.054 \mathrm{~mm}, N=44$; less than $2 \mathrm{~h}=6.19 \pm 0.15 \mathrm{~mm}, N=10$; $t=0.1 .77, P=0.08$ ), or the size difference between male and female (more than $2 \mathrm{~h}=0.59 \pm 0.074 \mathrm{~mm}, N=39$; less than $2 \mathrm{~h}=0.28 \pm 0.14 \mathrm{~mm}, N=9 ; t=0.185, P=0.07)$. However, the sample size for short copulations is small, and these data do show borderline significant trends for males to stay paired longer with larger females.

The 33 male-male mounts that occurred during the mixed-sex trials ranged in duration from 1 to $9,084 \mathrm{~s}$ $($ mean $=10.2 \pm 5.0 \mathrm{~s}$, median $=1.1 \mathrm{~s})$. Using the longest mount for each of the 26 different males that mounted another male, we found that although the directions of the relationships between male size measures and duration of the mount were similar to those in the all-male trials, the patterns were not significant (top size $b=-0.11$, $F_{1,22}=0.27, P=0.61$; bottom size $b=0.13, F_{1,23}=0.37$, $P=0.55$; size disparity $\left.b=0.16, F_{1,21}=0.55, P=0.46\right)$. Twenty-one of the $26(81 \%)$ males that mounted a male also mounted a female; for 16 of these 21 males (76\%), the male paired with a male before he paired with a female, and for $14 / 16$ (87\%) of these latter males, the subsequent male-female pairing lasted at least $2 \mathrm{~h}$. Thus, if a male paired with a male, typically he did so for a relatively brief time and then mated and remained paired with a female for an extended period of time.

\section{Discussion}

Our study suggests that male Japanese beetles of any size will attempt to mount other males. However, the size of the top male relative to the bottom male is important in determining how long the pair lasts and whether a male extends his aedeagus. Below, we attempt to explain their male-male pairing behavior by answering two questions. First, why do they mount another male? Second, why do they remain mounted on another male?

The answer to why males mount other males may lie in understanding the selection pressures resulting from their mating system. The mating system of Japanese beetles consists of both males and females mating multiple times, often with different individuals (Fleming 1972; Barrows and Gordh 1978; Tigreros and Switzer 2008). On food plants, the overall sex ratio is male biased and the sex ratio of the single beetles is even more so $(70 \%$ male; Switzer et al. 2001). The combination of a high population density on food plants (Fleming 1972; Switzer et al. 2001), widely distributed suitable oviposition sites (Fleming 1972), and last male sperm precedence (Ladd 1966, 1970b) leads to a situation in which males continually search for available females, copulate with them, and then guard the females from other males for a period of time (Barrows and Gordh 1978; Saeki et al. 2005a, b). Males do sometimes attempt to take over an already mounted female, but such contests can last for hours and are only successful a small percentage of the time (Kruse and Switzer 2007). Thus, a male's best evolutionary option may be to be the first male to find an available female. 
However, few obvious physical differences seem to exist between males and females for males to use in sexual discrimination. Consequently, the selection pressure to be first, in combination with relatively weak sexual discrimination, may lead to males mistakenly mounting other males.

Answering the second question, why males remain mounted on another male, is more problematic. In many species, same-sex mounts are very brief (e.g., Aiken 1981). In Japanese beetles, however, we found that although mounts were usually brief, occasionally mounts lasted over $2 \mathrm{~h}$. Based on the results of this study, our hypothesis is that male Japanese beetles have two main 'cues' available to them to distinguish non-virgin females from males: body size and copulation. These two cues, in combination with the fact that females may not immediately copulate with a male upon being mounted, may lead to extended mounts. We elaborate on this hypothesis below.

Body size may best be assessed when a male mounts another individual. The results of our all-male experiment suggest that males may use a relative size cue, rather than an absolute size cue, when assessing the size of the individual they mount. If the mounted individual is larger than the mounting male, they are more likely to (1) attempt to copulate and (2) persist in the copulation attempt. This willingness to persist may be an evolutionary consequence of females not immediately copulating when a male attempts to insert his aedeagus; we observed a short delay to copulation in our mixed-sex experiment. This latency has also been observed in other insect species; for example, Tribolium castaneum females need to lower their last sternite to accommodate the male's aedeagus insertion, which may give them some control over when the copulation occurs (Lewis and Iannini 1995). Our hypothesis predicts that one would observe longer durations of male-male pairing behavior in other species with weak sex differentiation and some latency to copulate on the part of the female; in these species, mount duration should be related to the competitiveness of the male (which would determine his likelihood of finding other mates) and the average copulation latency of females.

In contrast to size, successful copulation, for Japanese beetles at least, indicates that the mounted individual is female; we observed no aedeagus insertion, and consequently no sperm transfer, in male-male mounts. The use of copulation as a cue for sex determination may explain the relatively low percentage $(3 \%)$ of male-male pairs in the field (Switzer et al. 2004). For example, a male may attempt to copulate with other males, but upon successfully finding and copulating with a female, he will stop searching for a period of time while guarding the female. This idea is supported by the results of our mixed-sex experiment, in which we found that males that mounted a male typically did so prior to finding a female; once they found a female, they remained paired with her for over 2 h (see also Barrows and Gordh 1978). In the field, the number of male-male pairs being observed at one particular time could likely end up being relatively low, depending on the number of males looking for mates, the duration of the mount (which is usually short for male-male mounts and long for male-female mounts, and may be affected by temperature, light levels, and density; Saeki et al. 2005b; Switzer et al. 2008), the operational sex ratio, and the movement of males and females into and out of the area. Proper testing of this scenario would require a combination of theoretical and further empirical studies.

The existence of male-male mating mistakes begs the question of why selection has not resulted in clearer cues for sex discrimination. Although we have no direct evidence to test the idea, one might speculate that the male-male mounting behavior is not costly relative to the possibility of missing the chance of a successful copulation (Thornhill and Alcock 1983). Furthermore, because we observed a relatively low frequency of resistance by males to being mounted, we predict that the costs of being mounted for larger individuals are fairly low. Regardless of the magnitude of the costs, our results suggest that whatever costs that exist for mounting a male will be incurred more by smaller individuals (see also Aiken 1981) and whatever costs exist for being mounted will be incurred more by larger males. We made a simple model (Figure 3) that demonstrates that males of approximately average size will be incurring relatively high costs for both making mistakes and being mounted. Additionally, given that male-male pairing is more common in the afternoon than in the morning and evening (Switzer et al. 2004), these costs would be expected to vary with time of day as well. However, only investigations of male-male mount durations in the field, in combination with estimates of energetic, thermoregulatory, and opportunity costs, would allow us to make more definitive conclusions.

We have presented the hypothesis that male Japanese beetles use body size as a cue for sexual discrimination. An alternative possibility is that males use cuticular hydrocarbons present on females for sexual discrimination (e.g., Simmons and Alcock 2003). Although no evidence exists for Japanese beetles using cuticular hydrocarbons in this fashion, if females had such compounds, it is at least possible that males might acquire female hydrocarbons on their bodies after contact with females (either while mating in the field or during collecting). Future studies that test for the existence of cuticular hydrocarbons and assess their potential roles in sexual discrimination and malemale pairing behavior would be useful to address this possibility. However, even if present and used for sexual discrimination, cuticular hydrocarbons would not reduce 


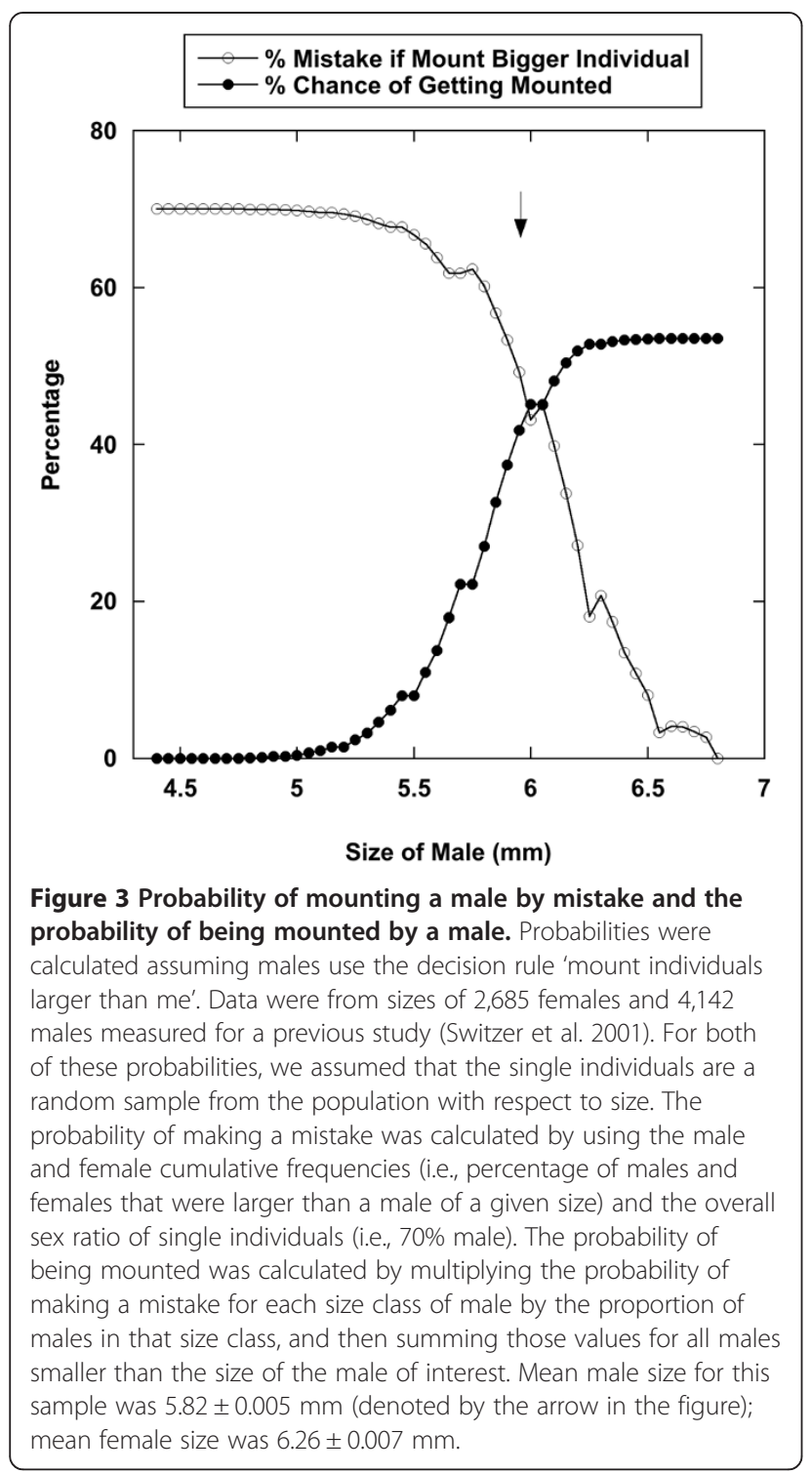

the behavior we observed to being a laboratory artifact; male-male pairing (with similar size patterns) occurs consistently under natural conditions in the field in Japanese beetles (Switzer et al. 2004).

Finally, our study of Japanese beetle male-male mounting behavior has interesting implications for their heterosexual behavior. Paired females are larger than unpaired females in the field (Switzer et al. 2001), both small and large males will mate with larger females when given a choice (Saeki et al. 2005c), and males tend to mate more quickly with larger females and guard larger females for longer periods of time (this study; Saeki et al. 2005b; Switzer et al. 2008). So, size also seems to be important in heterosexual mating behavior. Such preferences for pairing with large females may be adaptive for two, non-exclusive reasons. First, like many species, larger
Japanese beetle females produce more and/or larger eggs (Saeki et al. 2005c). Second, and perhaps more interestingly, larger individuals are more likely to be females. Therefore, one possible function of choosing larger females is to avoid males. This function is likely to apply in other species in which sex differentiation is not clear at mating time. For example, even in species that have a distinct sex pheromone, such as Diaprepes abbreviatus (Harari et al. 2000) or virgin female Japanese beetles (Ladd 1970a; Tumlinson et al. 1977), intense, competitive aggregations of males around the female may make it difficult for a male to determine which individual is actually producing the pheromone (Harari et al. 2000). In such circumstances, attempting to mate with larger individuals may function as much to avoid a homosexual pairing as to fertilize more eggs. These two explanations (female preference and male avoidance) will likely act simultaneously for Japanese beetles, for selection pressures to identify correctly a member of the opposite sex will reinforce the selection pressures to identify the 'best' mate possible (Ryan and Rand 1993). The relative strength of each selection pressure will likely depend on a particular social situation (e.g., sex ratio) experienced by males.

\section{Conclusions}

Male-male pairing in Japanese beetles likely results from a combination of relatively poor ability to differentiate the sexes and selection on males to mate quickly with available females. Males seem to attempt to mount other Japanese beetles indiscriminately with respect to size and sex. When pairing with a female, immediate copulation does not always occur, probably because of the role the female plays in the mating process. Because of the potentially greater benefit to be received by mating with larger females and/or because larger individuals are more likely to be female, males remain longer on larger potential mates, even if those mates are the incorrect sex. Future studies, investigating the possible role of chemical cues as well as the relative costs and benefits of male-male mounting behavior (particularly in the field under different environmental and social conditions), would extend our understanding of this interesting behavior.

\section{Competing interests}

The authors declare that they have no competing interests.

\section{Authors' contributions}

All authors contributed to all aspects of conducting and presenting this research. All authors read and approved the final manuscript.

\section{Acknowledgements}

We would like to thank E. Raboin, V. Shumaker, and I. and J. Switzer for assistance in collecting beetles and gathering the data. P. Eason, J. LaManna, and L. Switzer provided helpful comments on an earlier version of the manuscript. This study was partially supported by EIU Council of Faculty Research Grants to PVS, United States Department of Agriculture NRI Grant 
\#2005-35302-16364 to PVS, and United States Department of Agriculture NRI Grant \#2001-35311-11134 to PVS and KCK. This study complied with current institutional guidelines and laws of the United States of America.

\section{Author details}

'Department of Biological Sciences, Eastern Illinois University, Charleston, IL 61920, USA. ${ }^{2}$ Current address: Department of Natural and Applied Sciences, University of Wisconsin-Green Bay, Green Bay, WI 54311, USA.

\section{Received: 9 December 2013 Accepted: 11 August 2014}

\section{Published: 19 August 2014}

\section{References}

Aiken RB (1981) The relationship between body weight and homosexual mounting in Palmacorixa nana Walley (Heteroptera: Corixidae). Florida Entomol 64:267-271

Bagemihl B (1999) Biological Exuberance. St. Martin's Press, New York

Bailey NW, Zuk M (2009) Same-sex sexual behavior and evolution. Trends Ecol Evol 24:439-446

Barrows EM, Gordh G (1978) Sexual behavior in the Japanese beetle, Popillia japonica, and comparative notes on sexual behavior of other scarabs (Coleoptera: Scarabaeidae). Behav Biol 23:341-354

Dickinson JL (1992) Scramble competition polygyny in the milkweed leaf beetle: combat, mobility, and the importance of being there. Behav Ecol 3:32-41

Dickinson JL (1995) Trade-offs between postcopulatory riding and mate location in the blue milkweed beetle. Behav Ecol 6:280-286

Fleming WE (1972) Biology of the Japanese beetle. US Dep Agric Tech Bull 1449:1-129

Hankison SJ, Morris MR (2003) Avoiding a compromise between sexual selection and species recognition: female swordtail fish assess multiple species-specific cues. Behav Ecol 14:282-287

Harari AR, Brockmann HJ, Landolt PJ (2000) Intrasexual mounting in the beetle Diaprepes abbreviatus (L.). Proc R Soc Lond B 267:2071-2079

Kruse KC, Switzer PV (2007) Physical contests for females in the Japanese beetle, Popillia japonica. J Insect Sci 7:34, available online: insectscience.org/7.34

Ladd TL Jr (1966) Egg viability and longevity of Japanese beetles treated with tepa, apholate, and metepa. J Econ Entomol 59:422-425

Ladd TL Jr (1970a) Sex attraction in the Japanese beetle. J Econ Entomol 63:905-908

Ladd TL Jr (1970b) Mating competitiveness of male Japanese beetles sterilized with tepa. J Econ Entomol 63:438-439

Lewis SM, lannini J (1995) Fitness consequences of differences in male mating behaviour in relation to female reproductive status in flour beetles. Anim Behav 50:1157-1160

Loughrin JH, Potter DA, Hamilton-Kemp TR (1995) Volatile compounds induced by herbivory act as aggregation kairomones for the Japanese beetle (Popillia japonica Newman). J Chem Ecol 21:1457-1467

Maklakov AA, Bonduriansky R (2009) Sex differences in survival costs of homosexual and heterosexual interactions: evidence from a fly and a beetle. Anim Behav 77:1375-1379

Møller AP (1987) Extent and duration of mate guarding in swallows Hirundo rustica. Orn Scand 18:95-100

Pfennig KS (1998) The evolution of mate choice and the potential for conflict between species recognition and mate-quality recognition. Proc R Soc Lond B 265:1743-1748

Pfennig KS (2000) Female spadefoot toads compromise on mate quality to ensure conspecific matings. Behav Ecol 11:220-227

Potter DA, Held DW (2002) Biology and management of the Japanese beetle. Annu Rev Entomol 47:175-205

Ryan MJ, Rand AS (1993) Species recognition and sexual selection as a unitary problem in animal communication. Evolution 47:647-657

Saeki Y, Kruse KC, Switzer PV (2005a) Physiological costs of mate guarding in the Japanese beetle (Popillia japonica Newman). Ethology 111:863-877

Saeki Y, Kruse KC, Switzer PV (2005b) The social environment affects mate guarding behavior in Japanese beetles, Popillia japonica. J Insect Sci 5:18, available online: insectscience.org $/ 5.18$

Saeki Y, Kruse KC, Switzer PV (2005c) Male preference for large females and female reproductive condition in the Japanese beetle Popillia japonica (Coleoptera: Scarabaeidae). J Kansas Entom Soc 78:13-19

Scharf I, Martin OY (2013) Same-sex sexual behavior in insects and arachnids: prevalence, causes, and consequences. Behav Ecol Sociobiol 67:1719-1730
Shine R, Olsson MM, Mason RT (2000) Chastity belts in garter snakes: the functional significance of mating plugs. Biol J Linn Soc 70:377-390

Simmons LW, Alcock J (2003) The role of cuticular hydrocarbons in mate attraction and repulsion by female Dawson's burrowing bee Amegilla dawsoni. Anim Behav 66:677-685

Smith LB, Hadley C (1926) The Japanese beetle. U S Dept Agric Circular 363:1-67

Switzer PV, Escajeda K, Kruse KC (2001) Pairing patterns in Japanese beetles (Popillia japonica Newman): effects of sex ratio and time of day. J Insect Behav 14:713-724

Switzer PV, Forsythe PS, Escajeda K, Kruse KC (2004) Effects of environmental and social conditions on homosexual pairing in the Japanese beetle (Popillia japonica Newman). J Insect Behav 17:1-16

Switzer PV, Enstrom PC, Schoenick CA (2008) Environmental conditions affect sperm competition risk in Japanese beetles (Coleoptera: Scarabaeidae). Ann Entomol Soc Am 101:1154-1161

Thornhill R, Alcock J (1983) The Evolution of Insect Mating Systems. Harvard University Press, Cambridge

Tigreros N, Switzer PV (2008) Effects of food deprivation, body size, and egg load on the mating behavior of female Japanese beetles, Popillia japonica Newman (Coleoptera: Scarabaeidae). Ethol Ecol Evol 20:89-99

Tumlinson JH, Klein MG, Doolittle RE, Ladd TL, Proveaux AT (1977) Identification of the female Japanese beetle sex pheromone: inhibition of male response by an enantiomer. Science 197:789-792

Van Timmeren SJ, Switzer PV, Kruse KC (2000) Emergence and reproductive patterns in the Japanese beetle, Popillia japonica (Coleoptera: Scarabaeidae). Jan Entom Soc 74:17-27

doi:10.1186/s40555-014-0053-z

Cite this article as: Switzer et al: Male-male mounting and the unreliability of body size as a character for mate choice in male Japanese beetles (Popillia japonica Newman). Zoological Studies 2014 53:53

\section{Submit your manuscript to a SpringerOpen ${ }^{\odot}$ journal and benefit from:}

- Convenient online submission

$\checkmark$ Rigorous peer review

- Immediate publication on acceptance

- Open access: articles freely available online

- High visibility within the field

- Retaining the copyright to your article

Submit your next manuscript at $>$ springeropen.com 